\title{
Call for applications: graduate student researcher (PhD student) and postdoctoral associates on LCA research
}

\author{
Sangwon Suh
}

Received: 20 December 2013 / Accepted: 26 December 2013 / Published online: 23 January 2014

(C) Springer-Verlag Berlin Heidelberg 2014

\section{Synopsis}

Modern societies generate and mobilize chemicals of enormous diversity and quantity. However, our understanding of the life cycle environmental impacts of chemicals and materials has not kept pace with new discoveries or with the production scale of chemicals. Development of a rapid, early stage tool to evaluate life cycle impacts has a broad relevance to industry, government, and academic communities. We have received a significant amount of funding to develop the science, data, and the tool that will enable an open-access, online platform, the Chemical Life-Cycle Builder (CLB) for early stage life cycle environmental evaluation of chemicals and materials. We have 12 industrial, governmental, and academic partners throughout the world that will collaborate under this project. The project will be conducted by a multidisciplinary team of experts, representing life cycle assessment (LCA); database development; fate, transport, and toxicity modeling; chemical engineering and chemical process design; sustainable chemistry; and materials science. The project will be a crystallization of cutting-edge approaches from each of these fields and offers a fertile ground for world-class research. The $\mathrm{PhD}$ researchers and postdoctoral associates recruited for this project will be given the opportunity to participate in the research program, collaborate with our partners, and join our rich training and internship programs. Depending on the qualifications, we will provide

\footnotetext{
S. Suh $(\bowtie)$

Bren School of Environmental Science and Management, University of California, Santa Barbara, CA, USA

e-mail: suh@bren.ucsb.edu

URL: http://www.bren.ucsb.edu/academics/call_for_lca applications.htm
}

tuition, fees, stipend, travel funds, and other benefits for the $\mathrm{PhD}$ researchers and postdoctoral associates. For postdoctoral associates, we will offer a competitive salary commensurate with experience.

\subsection{Starting date}

For Graduate Student Researcher ( $\mathrm{PhD}$ students): Fall 2014 (September-October)

For Postdoctoral Associates: As soon as possible

\section{Qualifications}

2.1 For graduate student researcher (GSR) applicants to $\mathrm{PhD}$ program

- B.S. or M.S. degree in relevant fields including engineering, natural science, and management science.

- Good command of written and verbal English.

- Ability and willingness to work in collaborative, multidisciplinary environment.

- Proficiency in computer programing and database design is recommended but not required.

- Knowledge and understanding in LCA is desirable but not required.

\subsection{For postdoctoral associates}

- $\mathrm{PhD}$ in relevant fields including engineering, natural science, and management science.

- Intimate knowledge and understanding in life cycle assessment.

- Proven record of designing and writing scientific publications. 
- Good command of written and verbal English.

- Ability to manage a large project under a multidisciplinary environment.

\section{Application process}

For Graduate Student Researcher positions, the following documents should be sent to Prof. Sangwon Suh via email (suh@bren.ucsb.edu) by March 27, 2014.

For Postdoctoral Associate positions, application will be accepted until filled.

\section{- $\quad$ Statement of purpose}

- The statement of purpose should clearly outline your research interests and goals, your reasons for believing that your participation to this research program will enable you to achieve those goals, and your past experiences and how they have prepared you to be successful in a research-focused graduate program.
- CV including the following information:

- Education (degree, institution, year of completion)

- Other work experiences

- GPA (no official transcript needed at this stage)

- TOEFL or IELTS scores (either of the two, if applicable): University requires a minimum score of 550 (paper test) or 213 (computer test) for TOEFL and Overall Band Score of 7.0 or higher for IELTS. At this stage, no official mail from TOEFL or IELTS is required. Please simply indicate your score in your $\mathrm{CV}$.

- Graduate Record Examination (GRE) score: The average combined verbal and quantitative GRE score of applicants admitted to our program last year was approximately 316 (new score) or 1,350 (old score). There is no need to send the official mail from GRE. Please simply indicate your score in your CV.

- Relevant experiences

Publications

Presentations

Project experience 